\title{
Removal of arsenic from simulated groundwater by adsorption using iron-modified rice husk carbon
}

\author{
Son Van Dang ${ }^{1,2,3}$, Junjiro Kawasaki ${ }^{2}$, Leonila C. Abella ${ }^{1}$, Joseph Auresenia ${ }^{1}$, Hiroaki \\ Habaki $^{2}$, Pag-asa D. Gaspillo ${ }^{2}$, Hitoshi Kosuge ${ }^{2}$, Hoa Thai Doan ${ }^{3}$ \\ ${ }^{1}$ Department of Chemical Engineering, De La Salle University, 2401 Taft Avenue, 1004 Manila, \\ Philippines \\ 2 Department of Chemical Engineering, Tokyo Institute of Technology, 2-12-1 Ookayama, \\ Meguro-ku, Tokyo 152-8550, Japan \\ ${ }^{3}$ Department of Chemical Technology, Hanoi University of Technology, No.1 Dai Co Viet, Hai \\ Ba Trung, Hanoi, Vietnam
}

\begin{abstract}
This study focused on the removal of arsenic from simulated groundwater by batch adsorption using iron-modified rice husk carbon ( $\mathrm{RH}-\mathrm{Fe})$. The results showed that $\mathrm{RH}-\mathrm{Fe}$ was very effective in the removal of arsenic not only at low and moderate initial concentrations of arsenic (1.42 and $2.77 \mathrm{mg} / \mathrm{L}$ ) but also at very high initial concentrations of arsenic (4.61 and $7.38 \mathrm{mg} / \mathrm{L})$. The arsenic adsorption by $\mathrm{RH}-\mathrm{Fe}$ was dependent on $\mathrm{pH}$ and varied with arsenic initial concentration and adsorbent dose. Langmuir isotherm could describe the adsorption equilibrium and the adsorption capacity was found to be $2.24 \mathrm{mg} / \mathrm{g}$. The pseudo-second order kinetic model gave the best fit with the experimental data.
\end{abstract}

Keywords: Arsenate, Arsenite, Adsorption Isotherm, Adsorption Kinetics, Groundwater, Rice husk.

\section{INTRODUCTION}

Arsenic is well-known as the "king of poison". Long-term exposure can cause cancer of the skin, lungs and liver (Azcue and Nriagu, 1994). In view of this, the World Health Organization has set the standard for arsenic in drinking water as $0.01 \mathrm{mg} / \mathrm{L}$ (WHO, 1993). Arsenic can be found on earth in small concentrations. It occurs naturally in soil and minerals, and it may enter the air, water and land through wind-blown dust and water run-off.

Recently, arsenic (As) contamination of groundwater - one of the most important sources for drinking water- has become a major concern on a global scale, especially in Bangladesh, India and South-East Asia.

In groundwater, inorganic arsenic occurs primarily in two oxidation states or as oxyanion compounds, namely, arsenite (trivalent arsenic, As[III]) and arsenate (pentavalent arsenic, As[V]). As[III] is the predominant species under reducing conditions, more toxic and difficult to remove compared to As[V] (Jain and Ali, 2000; Robertson, 1989; Korte and Fermando, 1991).

There are several techniques to remove arsenic from groundwater: physico-chemical, biological, and membrane technologies. However, these techniques are either expensive

Address correspondence to Son Van Dang, Hanoi University of Technology

Email: sondang06@yahoo.com

Received September 17th, 2008, Accepted February 18th, 2009 
or difficult to apply in poor and rural areas. One of the promising and viable methods for arsenic removal is the adsorption technique where appropriate and readily available adsorbents are used.

Studies on the removal of arsenic from groundwater using rice husk (an agricultural waste which is a byproduct in rice milling) have been carried out by some researchers. Amin et al. (2006) investigated the usability of untreated rice husk packed in glass columns $(2 \mathrm{~cm} \times 30 \mathrm{~cm})$ for the removal of As[III] and As[V]. Lee et al. (1999) reported the removal of $80 \%$ arsenate from highly concentrated solutions $(100,000-$ $600,000 \mu \mathrm{g} / \mathrm{L})$ utilizing rice husks modified with ammonium to produce "quaternized rice husk" as adsorbents. A strong $\mathrm{pH}$ dependency ( $\mathrm{pH} 6-10)$ was observed and the estimated maximum sorption capacity of quaternized rice husk was $19 \mathrm{mg} / \mathrm{g}$. Mondal et al. (2007b) reported that both rice husk carbon (RH) and activated carbon (GAC) had lesser arsenic removal capacity, which could be considerably improved by surface modification via impregnation with metals, such as iron, manganese, aluminum, calcium, titanium or copper. Indeed, the adsorption capacity of rice husk carbon and its activated form was lesser by approximately 4.8-5.5 times as compared to that of the calcium-modified rice husk carbon (Mondal et al., 2007b).

Since the untreated rice husk carbon alone has been found to be not very effective in removing arsenic, it is necessary to improve its efficiency by modifying its adsorbing properties. It is well known that iron and its compounds are very effective as adsorbents in the removal of arsenic from water, but using iron alone may be very expensive, limiting its suitability in rural areas of poor countries. From the literature survey, there are very few studies on iron-modified rice husk carbon as adsorbent for the removal of arsenic from drinking water, although there are many research papers on arsenic removal using iron-based adsorbent. In this study, the surface of the rice husk carbon is modified by impregnation with iron. Moreover, most researches have been done using pure water instead of actual groundwater, especially for studies on the adsorption equilibrium and its kinetics. The results, therefore, may not be reflective of the true behavior in the actual treatment system. In addition, many researchers have used a linear regression method to estimate the isotherm coefficients which may cause errors due to the transformation of the non-linear isotherm equation (Langmuir, Freundlich isotherms) into a linear expression of the isotherm equation (Longhinotti et al., 1998). Thus, the non-linear regression method may be a better way to obtain the equilibrium isotherm coefficients (Kumar and Sivanesan, 2005).

This study aimed to develop a new adsorbent - iron-modified rice husk carbon (RH-Fe)which was prepared from an available, cheap source of carbon (rice husk carbon) and the most effective agent (iron) for the removal of both As[III] and As[V] from simulated groundwater using a mixture of $70 \% \mathrm{As}[\mathrm{III}]$ and $30 \% \mathrm{As}[\mathrm{V}]$ for all experiments. The effects of initial arsenic concentration, $\mathrm{pH}$, and adsorbent doses were investigated. The three most commonly used adsorption isotherms: Langmuir, Freundlich, LangmuirFreundlich, and the comparison of the isotherm coefficients from both linear and nonlinear regression methods were examined. Adsorption kinetics was also studied. 


\section{EXPERIMENT}

\section{Simulated groundwater}

A typical groundwater sample with average concentrations of the major components was simulated and used in this study. The major components of the simulated groundwater are shown in Table 1 as referred from previous work (Lien and Wilkin, 2005).

Table 1 Composition of simulated water

\begin{tabular}{cc}
\hline Composition & Concentration, mg/L \\
\hline $\mathrm{CaCl}_{2} \cdot 2 \mathrm{H}_{2} \mathrm{O}^{*}$ & 230 \\
$\mathrm{Na}_{2} \mathrm{SO}_{4}{ }^{*}$ & 1200 \\
$\mathrm{NaHCO}_{3}{ }^{*}$ & 370 \\
$\mathrm{MgCl}_{2} \cdot 6 \mathrm{H}_{2} \mathrm{O}^{*}$ & 135 \\
\hline
\end{tabular}

(* These chemicals are from Wako Pure Chemicals Ltd, Japan)

\section{Arsenic stock solution}

The stock solutions of arsenite (As[III]) were prepared from As[III] standard solution of $1003 \mathrm{mg} / \mathrm{L}$ (Wako Pure Chemicals Ltd., Japan) by dilution with distilled water. The stock solutions of arsenate (As[V]), containing $4.1646 \mathrm{mg}$ of $\mathrm{Na}_{2} \mathrm{HAsO}_{4} .7 \mathrm{H}_{2} \mathrm{O}$ (Wako Pure Chemicals Ltd, Japan), were mixed thoroughly with distilled water to make a total volume of $1000 \mathrm{~mL}$. The stock solution has an arsenic concentration of $1000 \mathrm{mg} / \mathrm{L}$.

\section{Preparation of Adsorbents}

Rice husk carbon (Kansai Co., Japan), with 50.36\% $\mathrm{SiO}_{2}, 40.49 \% \mathrm{C}, 1.04 \% \mathrm{H}$ and $0.42 \% \mathrm{~N}$, and with particle size of $100-340 \mu \mathrm{m}$, was washed with distilled water and dried at $105^{\circ} \mathrm{C}$ in an oven for $24 \mathrm{~h}$ (labeled as Washed-RH). The preparation of ironmodified RH was conducted in a similar way by Mondal et al. (2007a) in order to modify the activated carbon by impregnation with iron for the removal of arsenic. One hundred grams of Washed-RH was mixed with $\mathrm{Fe}^{3+}$ solutions containing the calculated amount of $\mathrm{Fe}\left(\mathrm{NO}_{3}\right)_{3} \cdot 6 \mathrm{H}_{2} \mathrm{O}$ (Wako Pure Chemicals Ltd., Japan) in $500 \mathrm{~mL}$ of distilled water. The corresponding percentage of iron on $\mathrm{RH}$ was $5 \%$ by weight. A $10 \% \mathrm{NaOH}$ solution was added to adjust the $\mathrm{pH}$ to 10 . The impregnation of iron onto $\mathrm{RH}$ took place in a temperature-controlled bath at $70^{\circ} \mathrm{C}$ until all the water evaporated completely. The residue was dried in an oven at $120^{\circ} \mathrm{C}$ overnight, cooled and washed with distilled water, and dried again for another $24 \mathrm{~h}$ in an oven at $105^{\circ} \mathrm{C}$.

The surface area for RH-Fe $5 \%$ was $320 \mathrm{~m}^{2} / \mathrm{g}$; the pore volume was $0.044 \mathrm{~cm}^{3} / \mathrm{g}$; and the pore size was $108.8 \AA$. These values were obtained by BET (Brunauer, Emmett and Teller) analysis. 



Figs.1a and 1b SEM (magnification of 2000x, width 66.0um) for original RH and iron-modified $\mathrm{RH}$

Figs. $1 a$ and $1 b$ show SEM (Scan Electron Microscopy) photographs of the original rice husk and 5\%iron-modified rice husk (RH-Fe5\%), respectively. The surface of the original RH appears clean (Fig. la on left side). In contrast, there are visible patches of iron particles stuck on the surface of the iron-modified RH and a thin dust layer of iron particles spreading as well on the whole surface of RH-Fe5\% (Fig. $1 b$ on right side). These could be the active sites for arsenic adsorption.

\section{Experimental procedure}

Batch experiments were conducted to investigate the effects of $\mathrm{pH}$ values within the range of 5-9, of initial arsenic concentrations within the range of $1.42-7.39 \mathrm{mg} / \mathrm{L}$ and of adsorbent doses within the range of $0.5-5.0 \mathrm{~g} / \mathrm{L}$, as well as equilibrium and adsorption kinetics in a series of $1000 \mathrm{~mL}$ flasks. Each flask contained adsorbents and simulated groundwater with the initial arsenic concentration at a given $\mathrm{pH}$. The flasks with the samples were stirred at $300 \mathrm{rpm}$ by the speed-controlled stirrer in the temperature-controlled baths for $148 \mathrm{~h}$ under room temperature $\left(25^{\circ} \mathrm{C}\right)$ and atmospheric condition. The samples were taken to be acidified and analyzed for residual arsenic concentration. Since trivalent arsenic (As[III]) is a major component of arsenic species in groundwater, a mixture of $70 \% \mathrm{As}[\mathrm{III}]$ and $30 \% \mathrm{As}[\mathrm{V}]$ was used in the experiments and the total arsenic content was analyzed by ICP-MS (Seiko SII).

\section{RESULTS AND DISCUSSION}

\section{Effect of $\mathbf{p H}$}

The $\mathrm{pH}$ is an important factor in the removal of arsenic by adsorption, especially by employing aluminum or iron-modified adsorbents. As $\mathrm{pH}$ changes, the charge associated with the arsenic components in solution changes and the charge state on the surface of adsorbent also varies with $\mathrm{pH}$. The different charge between arsenic components in the solution and the charge state on the surface of adsorbent is one of the major mechanisms for arsenic adsorption.

$\mathrm{RH}-\mathrm{Fe} 5 \%$ adsorbent contains iron which is known as one of the most effective elements for arsenic removal. In this work, it was observed that the efficiency of arsenic removal from groundwater depended on $\mathrm{pH}$ sensitively. Efficiency increased with increasing $\mathrm{pH}$ from 5 to 9 (Fig. 2). After $144 \mathrm{~h}$, at $4.62 \mathrm{mg} / \mathrm{L}$ of initial arsenic concentration and 2.5 
$\mathrm{g} / \mathrm{L}$ of adsorbent dose, the percentage removal of total arsenic was $68.77,81.99$ and $88.00 \%$ for $\mathrm{pH}$ of 5,7 and 9 , respectively. The same behavior was observed in the study by Mondal et al. (2007a) for the removal of arsenic by GAC-Fe (iron-modified granular activated carbon) where percentage removal was maximum in the $\mathrm{pH}$ range of 5-7 for $\mathrm{As}[\mathrm{V}]$ and $\mathrm{pH}$ range of 9-11 for $\mathrm{As}[\mathrm{III}]$.

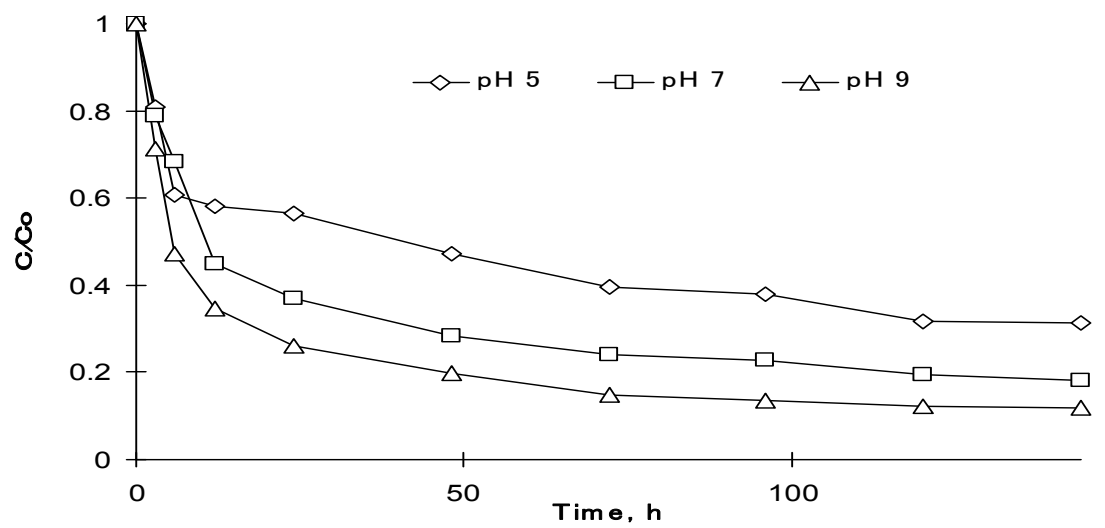

Fig. 2 Effect of $\mathrm{pH}$ on arsenic removal efficiency for samples containing RH-Fe $5 \%$,particle size of 0.1-0.35 mm, with Co of $4.62 \mathrm{mg} / \mathrm{L}$, adsorbent dose of $5 \mathrm{~g} / \mathrm{L}$

The mechanism can be attributed mainly to both adsorption affinity and chemical reaction. Adsorption affinity includes molecule-surface interaction, electrostatic interaction (i.e., ion exchange, coulombic attraction); while chemical reaction includes ligand exchange, surface complexation, covalent bonding, and Van der Waals forces (Gupta and Chen, 1978; Prasad, 1994; Korte and Fernando, 1991; Edwards, 1994; and Manning et al., 1998) These mechanisms may occur depending on the nature of the adsorbent and the existing forms of the arsenic species. Since there are many components in the adsorbent system (silica, carbon, and iron), the adsorption affinity and chemical reaction may occur simultaneously.

Surface charge results from protonation, dissociation, and/or surface complexation reactions of reactive surface hydroxyl groups at solid surfaces. The $\mathrm{pH}$ and ionic strength of solution determine the sign and magnitude of the solid surface charge. A negative charge develops on the molecule when dissociation occurs. The propensity for ionization is expressed by pKa- the constant of dissociation (which is a negative log, a smaller number shows a greater degree of dissociation). For arsenate and arsenite, pKa values are as follows (Bard et al., 1985):

For arsenate, $\mathrm{H}_{3} \mathrm{AsO}_{4} \quad \mathrm{pK}_{1}=2.19, \mathrm{pK}_{2}=6.94, \mathrm{pK}_{3}=11.5$.

For arsenite, $\mathrm{H}_{3} \mathrm{AsO}_{3} \mathrm{pK}_{1}=9.20, \mathrm{pK}_{2}=14.22, \mathrm{pK}_{3}=19.22$.

At the considered range of $\mathrm{pH}$ in this study ( $\mathrm{pH}$ 5-9), it can be seen that trivalent arsenic (As[III]) is stable at $\mathrm{pH} 0-9$ as neutral $\mathrm{H}_{3} \mathrm{AsO}_{3}$ which is indicated by the dissociation constant, $\mathrm{pKa}_{1}=9.20$; whereas pentavalent arsenic (As[V]) exists as the oxy-anions $\mathrm{H}_{2} \mathrm{AsO}_{4}{ }^{-}\left(\mathrm{pKa}_{2}=6.94\right)$ and $\mathrm{HAsO}_{4}{ }^{2-}\left(\mathrm{pKa}_{3}=11.5\right)$ (Bard et al., 1985). Since As[V] exists in the solution as negative ions, the adsorption of $\mathrm{As}[\mathrm{V}]$ may be a result of 
electrostatic attraction between anionic As[V] and the positively-charged iron on the surface of the adsorbent. On the other hand, although As[III] exists in the solution as a neutral compound $\left(\mathrm{H}_{3} \mathrm{AsO}_{3}\right)$, it may also be removed by chemical reaction occurring at pH 5-9 as follows:

$$
\begin{aligned}
& \mathrm{Fe}^{3+}+3 \mathrm{H}_{2} \mathrm{O} \rightarrow \mathrm{Fe}(\mathrm{OH})_{3}+3 \mathrm{H}^{+} \\
& \mathrm{Fe}(\mathrm{OH})_{3}+\mathrm{H}_{3} \mathrm{AsO}_{3} \rightarrow \mathrm{FeAsO}_{3} \cdot 2 \mathrm{H}_{2} \mathrm{O}+\mathrm{H}_{2} \mathrm{O}
\end{aligned}
$$

Hence, both forms of arsenic (As[III] and $\mathrm{As}[\mathrm{V}])$ are removed in the $\mathrm{pH}$ range of this study ( $\mathrm{pH}$ 5-9).

At the higher range of $\mathrm{pH}\left(\mathrm{pH}\right.$ 9-12), $\mathrm{As}[\mathrm{III}]$ changes from neutral $\mathrm{H}_{3} \mathrm{AsO}_{3}$ to negatively-charged $\mathrm{H}_{2} \mathrm{AsO}_{3}{ }^{-}$; $\mathrm{As}[\mathrm{V}]$ also has a negative charge. The negatively-charged arsenic ions and positively-charged adsorbent surface favor the arsenic adsorption by electrostatic attraction. These have been explained in detail by Ronald et al. (2005) and Mondal et al. (2007a).

The exact mechanism may be a complex combination of the different processes. All of the components in the adsorbent system used may participate in arsenic removal. The carbon in the RH-Fe adsorbent does not only act as a support material for iron attachment but also as an adsorbent where arsenic ions can be adsorbed by their affinity to the pores of carbon particles in the rice husk. Also, depending on the activation process used to prepare the adsorbent, carbon can be positively charged causing arsenic adsorption by electrostatic or coulombic attraction. As for the silica and silicate components of the adsorbent, the $\mathrm{pH}$ at the point-of-zero-charge for silica/silicate is very low compared to the considered $\mathrm{pH}$ range of 5-9 in this study. So within this range the silica/silicate may not provide active sites for arsenic adsorption by electrostatic interaction or coulombic attraction. However, with the existence of more than $50 \%$ of silica/silicate in the rice husk carbon, it may play a role as a support material for more uniform distribution of iron on the surface where iron active sites are more widely spread.

\section{Adsorption isotherm}

The distribution of arsenic between the liquid phase and the solid phase at equilibrium of the adsorption process can be described by the adsorption isotherm. Several adsorption isotherms based on different assumptions have been used. Among them, Langmuir and Freundlich isotherms, and the combination of these two isotherms known as Langmuir-Freundlich isotherm (Ho et al., 2002) are commonly used. To calculate the isotherm coefficients, linear and nonlinear regression methods are used for both Langmuir and Freundlich isotherms. However, for Langmuir-Freundlich isotherm, nonlinear regression method must be employed. Some available software for computers can be used for solving nonlinear regression problem. Microsoft Excel is used in this study.

\section{Freundlich}

The Freundlich isotherm presents an empirical adsorption isotherm for non-ideal sorption on heterogeneous surfaces and for multilayer sorption (where one active site of adsorbent can adsorb more than one molecule). This isotherm is expressed by the equation: 


$$
q_{e}=K_{F} C_{e}^{1 / n}
$$

A linear form of this expression is:

$$
\log q_{e}=\log K_{F}+\frac{1}{n} \log C_{e}
$$

where $q_{e}$ is the adsorbed amount of arsenic per gram of adsorbent at equilibrium ( $m g$ $A s / g$-adsorbent, $m g / g), C_{e}$ is equilibrium arsenic concentration in solution $(m g / L)$, $K_{F}(L / g)$ and $n$ are the Freundlich constants which represent the significance of adsorption capacity and intensity of adsorption, respectively. $K_{F}$ and $n$ are calculated from the intercept and slope of the plot $\log q_{e}$ and $\log C_{e}$. The values of Freundlich isotherm constants, as calculated from both linear and non-linear regression methods, are shown in Table 2.

Table 2 Comparison of adsorption isotherm coefficients

\begin{tabular}{ccccc}
\hline \multirow{2}{*}{ Isotherm } & \multicolumn{4}{c}{ Parameters } \\
\cline { 2 - 5 } & $\mathrm{Q}_{0}, \mathrm{mg} / \mathrm{g}$ & $\mathrm{K}$ & $1 / \mathrm{n}$ & $\mathrm{r}^{2}$ \\
\hline Freundlich & - & $(1.34)$ & $(0.45)$ & $(0.905)$ \\
& & 1.35 & 0.38 & 0.906 \\
\hline Langmuir & $(2.26)$ & $(1.79)$ & - & $(0.952)$ \\
& 2.24 & 1.92 & & 0.950 \\
\hline Langmuir-Freundlich & 2.06 & 2.74 & $\sim 1.00$ & 0.952 \\
\hline
\end{tabular}

Note: Values in parentheses () are from linear regression method, others are from non-linear regression method.

\section{Langmuir}

Langmuir isotherm presents a theoretical adsorption isotherm for ideal sorption on the homogeneous surface of solid adsorbent with mono-layer sorption (one site of adsorbent can adsorb only one molecule). This isotherm is expressed by the equation:

$$
q_{e}=\frac{Q_{0} K_{L F} C_{e}}{1+K_{L F} C_{e}}
$$

One of the linear expression forms is

$$
\frac{1}{q_{e}}=\frac{1}{Q_{0} K_{L}} \frac{1}{C_{e}}+\frac{1}{Q_{0}}
$$

where $q_{e}$ is the adsorbed amount of arsenic per gram of adsorbent at equilibrium ( $m g$ As $/ g$-adsorbent, $m g / g$ ), and $C_{e}$ is the equilibrium arsenic concentration in solution $(\mathrm{mg} / \mathrm{L}) . K_{F}$ is the Langmuir constant $(\mathrm{L} / \mathrm{mgs})$ and $Q_{0}$ represents the adsorption capacity of adsorbent, $(\mathrm{mg} / \mathrm{g}) . K_{L}$ and $Q_{0}$ are calculated from the intercept and slope of the plot $1 / q_{e}$ and $1 / C_{e}$. The values of the Langmuir isotherm constants, as calculated using the above equations, are shown in Table 2.

\section{Langmuir -Freundlich}

The combination of Langmuir and Freundlich isotherms is well known as Langmuir- 
Freundlich isotherm:

$$
q_{e}=\frac{Q_{0} K_{L F} C_{e}^{1 / n}}{1+K_{L F} C_{e}^{1 / n}}
$$

where $q_{e}$ is the adsorbed amount of arsenic per gram of adsorbent at equilibrium ( $m g$ As $/ g$-adsorbent, $\mathrm{mg} / \mathrm{g}$ ), and $C_{e}$ is the equilibrium arsenic concentration in solution $(\mathrm{mg} / \mathrm{L}) . K_{L F}(L / m g s)$ and $n$ are Langmuir-Freundlich constants, and $Q_{0}$, represents the adsorption capacity of adsorbent, $(\mathrm{mg} / \mathrm{g}) . K_{L F}$ and $Q_{0}$ are calculated using the nonlinear regression method. The results are presented in Fig. 5 and Table 2.



Fig.5 Non-linear plot for adsorption isotherms on arsenic removal for samples containing RH-Fe $5 \%$, particle size of $0.1-0.35 \mathrm{~mm}$, with Co of 1.42-7.38 $\mathrm{mg} / \mathrm{L}$, adsorbent dose of $2.5 \mathrm{~g} / \mathrm{L}, \mathrm{pH}$ of simulated groundwater ( $\mathrm{pH} 8.18$ ).

\section{Comparison of adsorption isotherms}

The values of the linear and nonlinear regression coefficient $r^{2}$ (Table 2) indicate that Langmuir and Langmuir-Freundlich isotherms exhibit best fit with the equilibrium experimental data for $\mathrm{RH}-\mathrm{Fe} 5 \%$. Hence, two of the most commonly used adsorption isotherms - Langmuir and Langmuir-Freundlich - may describe the adsorption process of arsenic by $\mathrm{RH}-\mathrm{Fe} 5 \%$. It can be noted as well that the values of the isotherm coefficients calculated by the two regression methods (linear and nonlinear) are different but not far away from each other, traceable to the linearized transformation problem. Indeed, Kumar and Sivanesan (2005) and Longhinotti et al. (1998) have shown that there are various types of linear expression forms, especially the Langmuir isotherm, which may give different results. In other words, the estimated value of Langmuir isotherm coefficients may depend on the type of Langmuir linear expression form used when linear regression method is applied. Therefore, non-linear regression may be an adequate method to obtain the equilibrium isotherm parameters utilizing the experimental data. The values of regression coefficients $r^{2}$ in Table 2 show that Langmuir and Langmuir-Freundlich isotherms give a better fit with equilibrium experimental data than the Freundlich isotherm. Also, the value of $1 / n$ from Langmuir- 
Freundlich isotherm is approximately one unit. Hence, Langmuir isotherm could describe the adsorption equilibrium of arsenic by $\mathrm{RH}-\mathrm{Fe}$. This observation indicates that one site of $\mathrm{RH}-\mathrm{Fe}$ adsorbent can just adsorb one arsenic molecule (monolayer adsorption) and a high value of constant $\mathrm{K}_{\mathrm{L}}(=1.92)$ also implies strong bonding of arsenic to the RH-Fe medium under the experimental conditions. However, the actual mechanism may be complex, involving more than one mechanism, such as ion exchange, surface complexation and electrostatical attraction as discussed in section 3.1. In other words, the removal of arsenic from simulated groundwater by $\mathrm{RH}-\mathrm{Fe} 5 \%$ conforms to Langmuir isotherm with an adsorption capacity of $2.24 \mathrm{mg} / \mathrm{g}$ for $Q_{0}$ of Langmuir isotherm.

Many adsorbents have been studied for arsenic removal from groundwater. A lot of results have been published where some adsorbents have been reported to have very high adsorption capacity at certain experimental conditions. However, Mohan and Pittman (2007) have indicated that direct comparisons of the tested adsorbents are largely impossible due to lack of consistency in the literature data, since the adsorption capacities have been evaluated at different $\mathrm{pH}$, temperatures, As[III]/As[V] ratios and the computed methods (Langmuir or the Freundlich isotherm or experiment). Moreover, even if some adsorbents have very high adsorption capacity, their applicability still seems difficult and unfeasible in real systems of arsenic treatment, especially for rural areas in poor countries. Rice husk and rice husk carbon are common by-products from agriculture, which are abundant in many countries, especially in Asia. These should be considered as cheap, available and ready-to-use adsorbents. Therefore, the adsorption capacity of RH-Fe $(2.24 \mathrm{mg} / \mathrm{g})$ in this study is reliable compared to several other similar low-cost adsorbents.

\section{Adsorption kinetics}

A good understanding of batch adsorption kinetics is needed for the design and operation of adsorption columns in real scale-up system for arsenic treatment. The nature of the arsenic adsorption kinetic process depends on the physical or chemical characteristics of the adsorbent and also on the operating conditions. The two most popular adsorption kinetic models, pseudo-first order and pseudo-second order have been used by some previous studies to describe the process kinetics of arsenic adsorption (Ho et al., 2000). In this present study, the applicability of the pseudo-first order (Lagergren model) and pseudo-second order kinetics (Ho model) are examined for the arsenic adsorption process using RH-Fe5\%. The fitted method is based on the regression correlation coefficient, $r^{2}$ values.

\section{Pseudo-first order kinetics}

The pseudo-first order kinetics model, derived by Lagergren in 1898, can be used to describe the rate of arsenic adsorption process, as follows (Ho et al., 2000):

$$
\frac{d q}{d t}=k_{1}\left(q_{e}-q\right)
$$

where $q$ is the amount of arsenic adsorbed $(\mathrm{mg} / \mathrm{g})$ at time $t, q_{\mathrm{e}}$ is the amount of arsenic adsorbed $(\mathrm{mg} / \mathrm{g})$ at equilibrium; $k_{l}$ is the observed adsorption rate coefficient $\left(s^{-1}\right)$. The linear expression form is expressed as: 


$$
\log \left(\frac{q_{e}}{q_{e}-q}\right)=-\frac{k_{1}}{2.303} t
$$

A plot of pseudo-first order kinetics is shown in Fig. 6 and the rate constant $k_{1}\left(s^{-1}\right)$ can be calculated from the plot of $\log \left(q_{e} / q_{e}-q\right)$ versus time $t$.

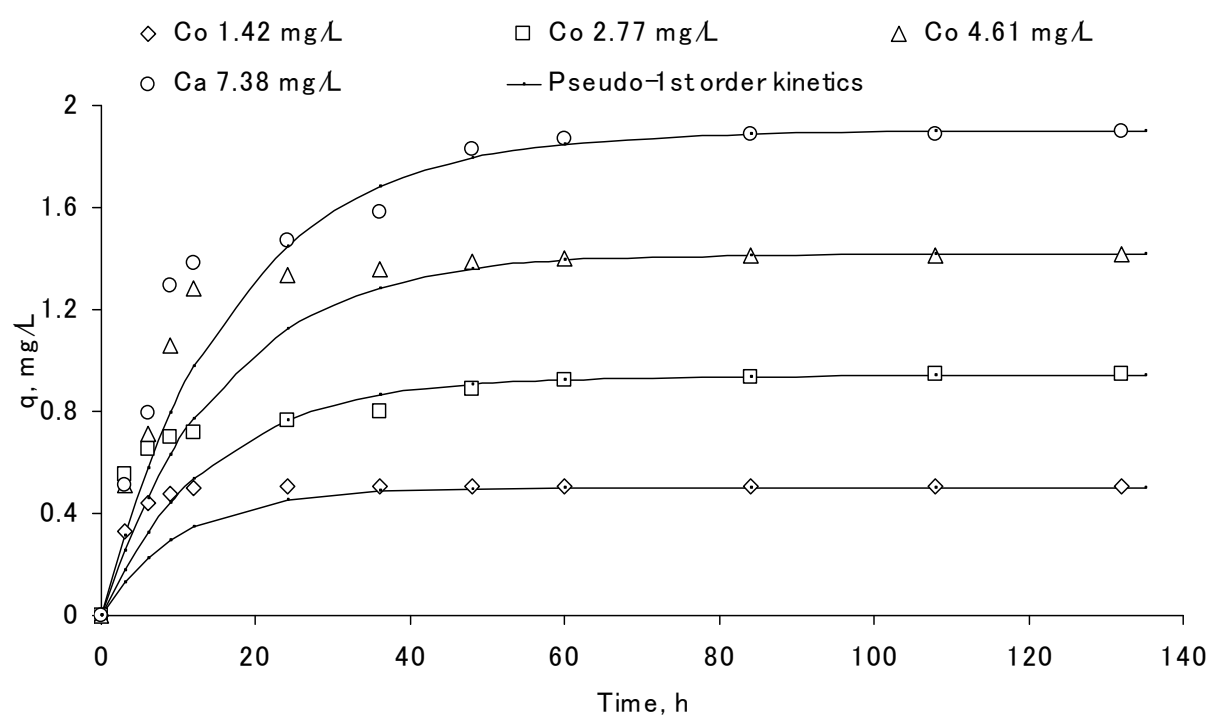

Fig.6 Plot of pseudo- $1^{\text {st }}$ order kinetics on arsenic removal for samples containing RH-Fe5\%, particle size of 0.1-0.35 mm, with adsorbent dose of $2.5 \mathrm{~g} / \mathrm{L}, \mathrm{pH}$ of simulated groundwater ( $\mathrm{pH} 8.18$ )

Also, the values of pseudo-first order kinetics coefficients as calculated from the plots are shown in Table 3.

Table 3 Value of rate coefficients for pseudo-first order kinetics

\begin{tabular}{cccc}
\hline Adsorbent & $\begin{array}{c}\text { Initial As } \\
\text { concentration }\end{array}$ & $\begin{array}{c}\mathbf{k}_{\mathbf{1}} \\
\left(\mathbf{s}^{-1}\right)\end{array}$ & $\mathbf{r}^{\mathbf{2}}$ \\
\hline & $1.42 \mathrm{mg} / \mathrm{L}$ & 0.100 & 0.441 \\
$\mathrm{RH}-\mathrm{Fe} 5 \%$ & $2.77 \mathrm{mg} / \mathrm{L}$ & 0.070 & 0.907 \\
& $4.61 \mathrm{mg} / \mathrm{L}$ & 0.065 & 0.794 \\
& $7.39 \mathrm{mg} / \mathrm{L}$ & 0.060 & 0.907 \\
\hline
\end{tabular}

\section{Pseudo-second order kinetics}

It can be seen from linear regression correlation coefficients, $r^{2}$ values, that the first-order kinetics does not fit the experimental data for $\mathrm{RH}-\mathrm{Fe} 5 \%$. Therefore, the adsorption kinetics of the process should be further analyzed. Assuming that the rate of arsenic adsorption process using $\mathrm{RH}-\mathrm{Fe} 5 \%$ follows the pseudo-second order kinetics, first used by Ho et al. (2000) as given below: 


$$
\frac{d q}{d t}=k_{2}\left(q_{e}-q\right)^{2}
$$

the linear expression form is:

$$
\frac{t}{q}=\frac{1}{k_{2} q_{e}{ }^{2}}+\frac{1}{q_{e}} t
$$

From plot between $t / q$ versus $t$, the value of the constants $k_{2}(\mathrm{~g} / \mathrm{mg} s)$ and $q_{\mathrm{e}}(\mathrm{mg} / \mathrm{g})$ can be calculated (Table 4).

Table 4 Value of rate coefficients for pseudo-second order kinetics

\begin{tabular}{ccccc}
\hline Adsorbent & $\begin{array}{c}\text { Initial As } \\
\text { concentration }\end{array}$ & $\begin{array}{c}\mathbf{q}_{\mathbf{e}}, \\
(\mathbf{m g} / \mathbf{g})\end{array}$ & $\begin{array}{c}\mathbf{k}_{\mathbf{2}}, \\
\text { (g/mg.s) }\end{array}$ & $\mathbf{r}^{\mathbf{2}}$ \\
\hline \multirow{3}{*}{$\mathrm{RH}-\mathrm{Fe} 5 \%$} & $1.42 \mathrm{mg} / \mathrm{L}$ & 0.51 & 2.89 & 0.999 \\
& $2.77 \mathrm{mg} / \mathrm{L}$ & 0.98 & 0.24 & 0.999 \\
& $4.61 \mathrm{mg} / \mathrm{L}$ & 1.47 & 0.19 & 0.999 \\
& $7.38 \mathrm{mg} / \mathrm{L}$ & 2.03 & 0.07 & 0.998 \\
\hline
\end{tabular}

A plot of pseudo-second order kinetics is shown in Fig. 7



Fig. 7 Plot of pseudo- $2^{\text {nd }}$ order kinetics on arsenic removal for samples containing $\mathrm{RH}-\mathrm{Fe} 5 \%$, particle size of $0.1-0.35 \mathrm{~mm}$, with adsorbent dose of $2.5 \mathrm{~g} / \mathrm{L}, \mathrm{pH}$ of simulated groundwater $(\mathrm{pH} 8.18)$

\section{Comparison of adsorption kinetics}

The calculated values of the observed rate coefficients $k_{1}, k_{2}$, and $q_{\mathrm{e}}$ of pseudo-first order and pseudo-second order kinetics and the corresponding linear regression correlation coefficient $r^{2}$ are shown in Tables 3 and 4. It can be seen that while the values of $r^{2}$ for the pseudo-first order range from 0.441 to 0.907 , those for the pseudosecond order are close to one unit. This means that the pseudo-second order kinetics shows better fit with the experimental data for RH-Fe $5 \%$, indicating the applicability of the pseudo-second order rate model in predicting the kinetics of arsenic adsorption onto $\mathrm{RH}-\mathrm{Fe} 5 \%$. Indeed, Azizian (2004) has reported that the sorption process obeys the 
pseudo-first order kinetics at high initial concentration of the solute and the pseudosecond order kinetics model at lower initial concentration of solute. In this study, the pseudo-second order kinetic expression is tested for predicting the amount of arsenic adsorbed for the overall adsorption time. The $q_{e}$ is predicted by applying the calculated kinetic coefficients in their corresponding kinetic expressions. These predicted values of $q_{e}$ can be compared with $q_{e}$ from the experimental data. The values from the model and experiment are not far from each other (Table 5). However, it is necessary to note that the observed rate coefficients from pseudo-first order and pseudo-second order kinetic models, $k_{1}$ and $k_{2}$, are not the intrinsic rate coefficients. They represent not only the combinations of adsorption and de-sorption rate constants, but also the complex functions of initial concentration of the solute (Azizian, 2004).

Table 5 Comparison of $\mathrm{q}_{\mathrm{e}}$ from second order model and experiment

\begin{tabular}{cccc}
\hline Adsorbents & $\begin{array}{c}\text { Initial As } \\
\text { concentration }\end{array}$ & $\begin{array}{c}\mathbf{q}_{\mathrm{e}},(\mathbf{m g} / \mathbf{g}) \\
\text { from } \\
\text { model }\end{array}$ & $\begin{array}{c}\mathbf{q}_{\mathrm{e}},(\mathbf{m g} / \mathbf{g}) \\
\text { from } \\
\text { experiment }\end{array}$ \\
\hline \multirow{2}{*}{$\mathrm{RH}-\mathrm{Fe} 5 \%$} & $1.42 \mathrm{mg} / \mathrm{L}$ & 0.51 & 0.50 \\
& $2.77 \mathrm{mg} / \mathrm{L}$ & 0.98 & 0.94 \\
& $4.61 \mathrm{mg} / \mathrm{L}$ & 1.47 & 1.42 \\
& $7.38 \mathrm{mg} / \mathrm{L}$ & 2.03 & 1.90 \\
\hline
\end{tabular}

\section{CONCLUSION}

A study was done on the use of $\mathrm{RH}-\mathrm{Fe} 5 \%$ as an adsorbent for the removal of an arsenic mixture $(70 \% \mathrm{As}[\mathrm{III}]$ and $30 \% \mathrm{As}[\mathrm{V}])$ from simulated groundwater. The adsorption of arsenic using $\mathrm{RH}-\mathrm{Fe} 5 \%$ was sensitively affected by $\mathrm{pH}$, the efficiency was better at $\mathrm{pH}$ 9. Using non-linear regression method, the experimental data for equilibrium study were well=fitted with Langmuir isotherm and the adsorption capacity was $2.24 \mathrm{mg} / \mathrm{g}$. The adsorption process could be expressed by the pseudo-second order kinetics because this kinetic model gave the best fit with the experimental data.

Generally, RH-Fe can be an effective adsorbent which may remove arsenic efficiently at $\mathrm{pH}$ of groundwater (8 - 9). Moreover, $\mathrm{RH}$ is just a biomass waste or by-product from agricultural production. Therefore, $\mathrm{RH}-\mathrm{Fe}$ may be considered as a cheap and available adsorbent for the removal of arsenic from groundwater. The use of this RH-Fe adsorbent may be feasibly implemented in the rural areas, especially in developing and poor countries.

\section{ACKNOWLEDGEMENT}

The research was supported by AUN/SEED-Net-JICA and all activities were carried out in Prof. Junjiro Kawasaki's Laboratory, Tokyo Institute of Technology, Japan. For this assistance, the research team expresses its most sincere gratitude. 


\section{REFERENCES}

Amin, M. N., S. Kaneco, T. Kitagawa, A. Begum, H. Katsumata, T. Suzuki and K. Ohta (2006). Removal of Arsenic in Aqueous Solutions by Adsorption onto Waste Rice Husk. Ind. Eng. Chem. Res., 45, 8105- 8110.

Azcue, J. M. and J. O. Nriagu (1994). Arsenic Historical Perspective, Arsenic in Environment. John Wile \& Sons, London, U.K., 1999.

Azizian, S. (2004). Kinetic models of sorption: a theoretical analysis. Journal of Colloid and Interface Science, 276, 47-52.

Bard, A. J., R. Parsons and J. Jordan (1985). Standard Potentials in Aqueous Solutions, pp.162, Marcel Dekker, New York, U.S.A., 1985.

Edwards, M. (1994). Chemistry of arsenic removal during coagulation and Fe-Mn oxidation. $J$. American Water Works Association, 86 (9), 64-78.

Ferguson, J. F. and J. Gavis (1972). A review of the arsenic cycle in natural Waters. Water Res., 6, $1259-1274$.

Gupta, S. and K. Chen (1978). Arsenic removal by adsorption. J. Water Poll. Contr. Fed., 50, $493-$ 506.

Ho, Y. S., G. McKay, D. A. J. Wase and C. F. Foster (2000). Study of the sorption of divalent metal ions on to peat. Adsorp. Sci. Technol, 18, 639-650.

Ho, Y. S., J. F. Porter and G. Mckay (2002). Equilibrium isotherm studies for the sorption of divalent metal ions peat copper, nickel and lead single component system. Water, Air, and Soil Pollution, 141, 1-33.

Jain, C. K. and I. Ali (2000). Arsenic: occurrence, toxicity and speciation techniques. Water Research, 34(17), 4304-4312

Korte, N. E. and Q. Fernando (1991). A review of arsenic (III) in groundwater. Crit. Rev. Environ. Control, 21(1), 1-39

Kumar, K. V. and S. Sivanesan (2005). Prediction of optimum sorption isotherm: Comparison of linear and non-linear method. Short communication, Journal of Hazardous Materials, B126, 198-201.

Lee, C., K. Low, S. Liew and C. Choo (1999). Removal of arsenic(V) from aqueous solution by quaternized rice husk. Environmental Technology, 20(9), 971-978.

Lien, H. and R. T. Wilkin (2005). High-level arsenate removal from groundwater by zero-valent iron. Chemosphere, 59, 377-386.

Longhinotti, E., F. Pozza, L. Furlan, M.N.M. Sanchez, M. Klug, M.C.M. Laranjeira and V.T. Farere (1998). Adsorption of Anionic Dyes on the Biopolymer Chitin. J. Braz. Chem. Soc., 9, 435-440

Manning, B. A. and S. Goldberg (1997). Adsorption and Stability of Arsenic (III) at the Clay Mineral-Water Interface. Environ. Sci. Technol., 31(7), 2005-2011.

Mohan D. and Pittman C.U. (2007). Arsenic removal from water/wastewater using adsorbents - a critical review. Journal of Hazardous Materials 142, 1-53.

Mondal, P., C. B. Majumder and B. Mohanty (2007a). A laboratory study for the treatment of arsenic, iron, and manganese bearing ground water using Fe3+ impregnated activated carbon: Effects of shaking time, $\mathrm{pH}$ and temperature. J. Hazard. Mater., 144, 420-426.

Mondal, P., C. B. Majumder and B. Mohanty (2007b). Removal of Trivalent Arsenic (As[III]) from Contaminated Water by Calcium Chloride (CaCl2)-Impregnated Rice Husk Carbon. Ind. Eng. Chem. Res., 46, 2550-2557.

Prasad, G. (1994). Removal of As(V) from aqueous systems by adsorption onto geological materials. 
Arsenic in the Environment, Vol. 26, pp. 33-154, John Wiley \&Sons, New York, U.S.A., 1994.

Robertson, F. N. (1989). Arsenic in Groundwater Under Oxidizing Conditions, Southwest United States. Environmental Geochemistry and Health, 11(3/4), 171-185.

Ronald, L., J. Vaughan and B. E. Reed (2005). Modeling As(V) removal by a iron oxide impregnated activated carbon using the surface complexation approach. Journal of Hazardous Materials, B126, 198-201.

WHO (World Health Organization); Guidelines for Drinking Water Quality, Vol. 1: Recommendations, WHO, Geneva, 1993, ISBN 924154460. 